\title{
Studies on the effect of vagotomy on small intestinal motility using the radio-telemetering capsule
}

\author{
B. ROSS, B. W. WATSON, AND A. W. KAY \\ From the University Department of Surgery, Royal Infirmary, Sheffield, and \\ the Regional Medical Physics Department
}

EDITORIAL SYNOPSIS The radio-telemetering capsule (radio-pill) has been used to study the return of motility in the small bowel after vagotomy with a drainage procedure, gastric operations not involving vagotomy, and non-gastric operations.

Small intestinal movements returned in about 10 hours after vagotomy, about four hours after the various gastric operations, and within one hour in those operations not involving handling of the viscera.

The implications of these results are discussed in relation to the management of patients after gastric surgery.

Vagotomy is now widely used in the treatment of duodenal ulceration. While much is known about the effects of this operation on gastric acid secretion, there have been few reports of its effect on gastrointestinal motility. This is especially true of effects on small bowel activity and has been due, in large measure, to the technical difficulties involved in its study.

That vagotomy has a profound effect on gastric motility is a matter of clinical experience: fullness, foul eructations, and vomiting following simple vagotomy led to the appreciation of the need to perform an associated drainage operation. Inhibition of gastric motor activity after vagotomy has been confirmed by balloon kymographic studies (Illingworth and Kay, 1947). By contrast, difference of opinion exists on the degree and duration of small bowel paralysis following section of the vagus nerves in man.

Methods of studying small bowel motility have included balloon kymography, the use of openended tubes, and simple auscultation which may be combined with continuous tape recording (Baker and Dudley, 1961). The first two methods, which entail passing lengthy tubes, are by no means free from discomfort to the patient and cannot therefore be regarded as physiologically acceptable. The last method can, at best, provide crude measurements of small bowel activity. The radio-telemetering capsule, a device first described in this country by Rowlands and Wolff (1960), has recently been modified and shown to be a scientifically reliable research tool
(Watson, Ross, and Kay, 1962). It is readily swallowed, causes no discomfort to the patient, and satisfies physiological requirements.

This paper reports an investigation designed to study the effect of vagotomy on small bowel pressure using the radio-telemetering capsule.

\section{METHODS}

CliniCAL MATERIAL Male patients aged 30 to 65 years were selected for study. In a first group of 11 patients disabling duodenal ulcer was treated by vagotomy and a drainage operation. Confirmation of vagotomy was obtained from an insulin test using the criteria of Hollander (1946); complete vagotomy was confirmed in all of this group. In a second group of 11 patients an operation was performed on the upper gastro-intestinal tract which did not involve complete vagotomy (gastrectomy, 5; pylorotomy, 5; gastrojejunostomy, 1). The mean ages of patients in these two groups differed by 0.8 year (average age, 49 years). In a third group of four patients the operation did not involve handling of the abdominal viscera (herniorrhaphy, 3; haemorrhoidectomy, 1).

ANAESTHETIC AGENTS All patients received pre-operative medication with atropine, $0.65 \mathrm{mg}$., and either morphine sulphate, $16 \mathrm{mg}$., or pethidine hydrochloride, $100 \mathrm{mg}$. Anaesthesia was induced with thiopentone sodium and succinylcholine chloride. Maintenance anaesthesia involved the use of halothane, pethidine, and muscle relaxants as the condition of the patient dictated. Immediately before completion of the operation atropine sulphate, $0.65 \mathrm{mg}$., and prostigmine, $15 \mathrm{mg}$., were given to reverse the residual effects of the muscle relaxant. 
SITE OF RELEASE OF THE CAPSULE A radio-pill was placed in the lumen of the small intestine at operation on patients in the first and second groups, the two selected sites varying with the operation. In those in whom the gastroduodenal region was opened the pill was placed in the duodenum and, after completion of the anastomosis, was milked along to the duodeno-jejunal flexure. When gastrojejunal anastomosis was performed, the radio-pill was placed in the efferent loop and was positioned approximately 6 in. distal to the anastomosis. Thus, in each case, the pill was placed in the proximal small bowel distal to the site of surgery.

In the third group the radio-pill was positioned at a similar point in the small bowel. The capsule, attached to a piece of thin thread approximately $150 \mathrm{~cm}$. in length, was swallowed four hours before the operation. The attachment of the thread was facilitated by a perforated screw cap at the battery end of the capsule. The pill was swallowed without difficulty when the patient was given 50 to $100 \mathrm{ml}$. of water to drink. The water was kept warm $\left(40\right.$ to $60^{\circ} \mathrm{C}$.), since ingestion of cold water is known to induce gastric motor inhibition (Kay, 1947) which, in turn, tends to prevent passage of the pill through the pylorus. The patient then lay on his right side to encourage transit of the capsule from the stomach; in all cases, this occurred within two hours. The capsule was then allowed to pass a distance of $120 \mathrm{~cm}$. from the lips. The thread was cut and swallowed immediately before induction of anaesthesia. Thus the pill lay freely in the upper small bowel as in the first and second groups.

POST-Operative management Patients in the first two groups were treated in the post-operative period by continuous gastric suction, intravenous fluids, and opiate analgesia; those in the third group had opiate analgesia only. Similar analgesia was arranged in all cases with either pethidine hydrochloride, $100 \mathrm{mg}$., or morphine sulphate, $16 \mathrm{mg}$., given intramuscularly. In order that the third group would be comparable with the other groups, these patients were given the analgesic at the same time after operation, even if pain was not troublesome.

RECORDING TECHNIQUE The radio-pill and receiving apparatus used have been described by Watson et al. (1962). The results were recorded on a standard recording milliameter. A pressure calibration of the pill, using the actual receiver and recorder to be used in the investigation, was carried out in water at $98^{\circ} \mathrm{F}$. before each study. A. small aerial was placed on the abdomen to receive the signals emanating from the pill. Recording of the signals began as soon as the patient returned to the ward from the operating theatre (within 30 minutes of completion of the operation).

Patients were kept under continuous observation during the period of the investigation. This was necessary in order that pressure changes could be positively identified as arising in the small intestine in contrast to artefacts from irregular respiration, or movements by the patient. The radio-pill was recovered by instructing the patient to use a bed pan for the purpose of defaecation. The interval, in days, between the operation and recovery of the pill was recorded.

\section{RESULTS}

Examples of the types of pressure waves recorded are shown in Figures 1 to 3 . In all cases, immediately after the operation, there was a period in which observed pressure changes were arising outside the small intestine-straining, coughing, vomiting, etc. Thereafter, pressure waves, which correspond to the type 1 waves of Code, Hightower, and Morlock (1952) and have a frequency of 10 to 12 /minute with no alteration in the basal pressure, were commonly observed (Fig. 1); these waves do not represent peristalsis. The next phase was characterized by waves corresponding to the type 3 waves of Code $e t$ al., having the same frequency as type 1 waves but with an associated rise in the basal pressure (Fig. 2); these waves represent peristalsis. Occasionally the type 3 waves were the first pressure waves to return. The type 3 waves over the succeeding hours became more irregular, frequent, and more prolonged (Fig. 3).

It was noticed that 'losses' of the radio-pill were associated with the presence of type 3 waves (Fig. 4). These occur when the electromagnetic axis of the pill becomes aligned at right angles to that of the aerial. This indicates spinning of the capsule and that it is being moved within the small bowel lumen.

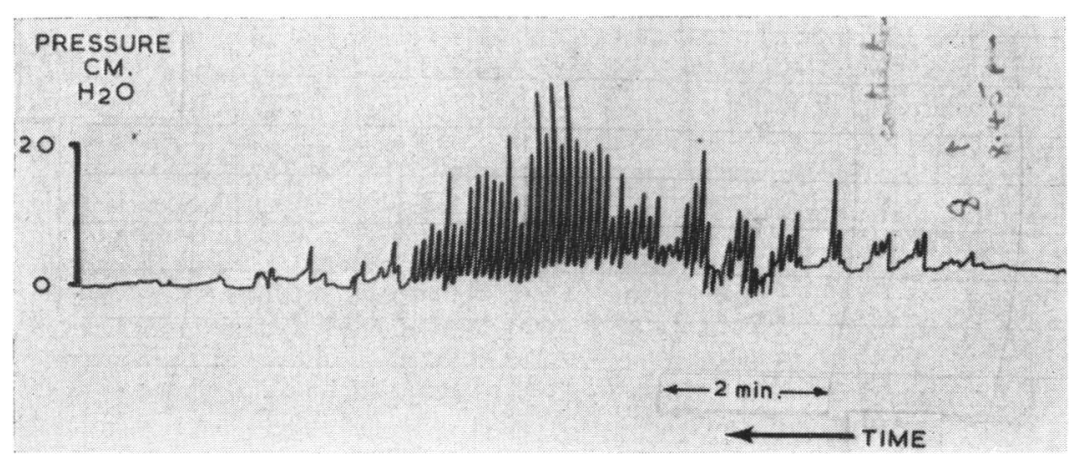

FIG. 1. The record reads from right to left. Small intestinal pressure waves with a frequency of 10 to $12 /$ minute and no rise in the basal pressure (type 1 waves). There is a slight fall in the base line from right to left produced by drift in the radio-pill. 


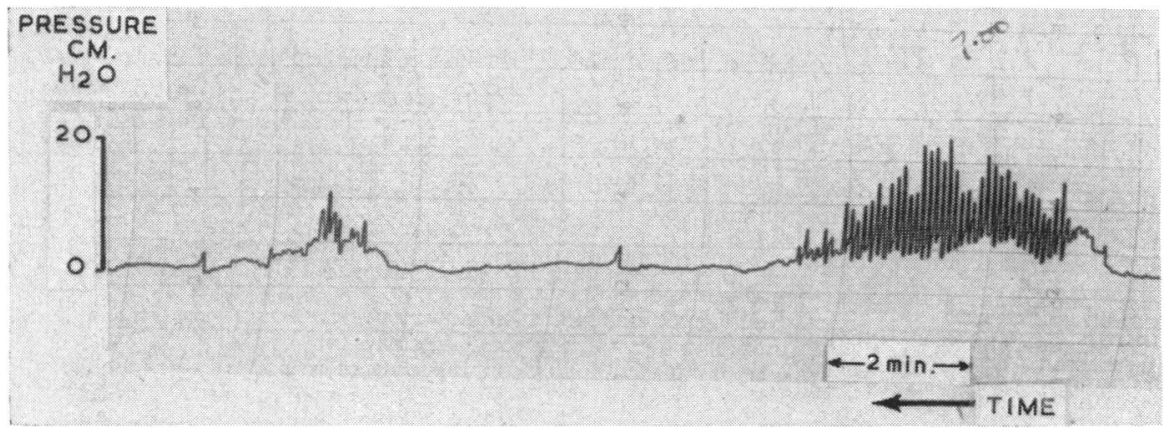

FIG. 2. The record reads from right to left. Small intestinal pressure waves with a frequency of 10 to $12 /$ minute and a rise in the basal pressure; this represents peristalsis (type 3 waves).

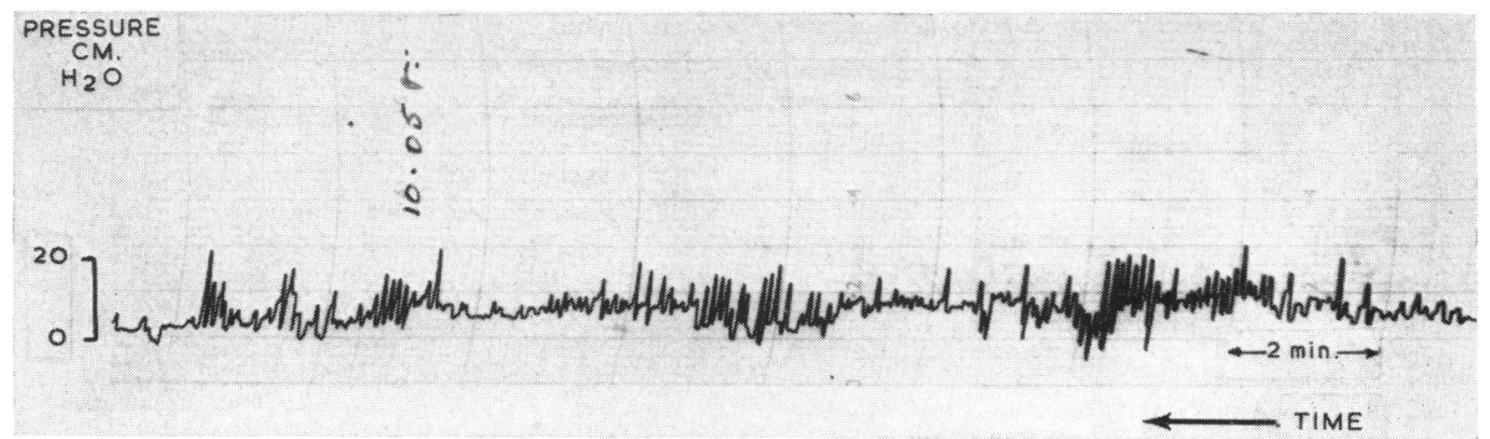

FIG. 3. The record reads from right to left. The appearance of the type 3 pressure waves several hours after return.

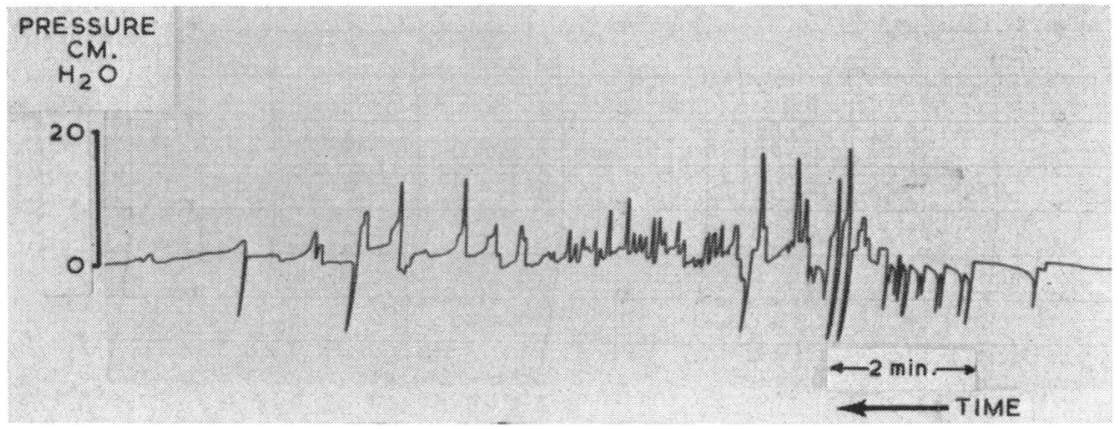

FIG. 4. The record reads from right to left. A sequence of type 3 pressure waves obscured by downward deflections resulting from 'losses' of the radio-pill signal.

In each patient, the criterion selected for return of peristalsis was that there should be waves with a frequency of 10 to 12 /minute associated with a rise in the basal pressure continuing for at least two minutes, as shown in Figure 2.

The times at which peristalsis returned are shown in Tables I and II. On consideration of Table I, it is apparent that vagotomy inhibits the return of small bowel motility for a longer period than gastric operations not involving vagal section. These results have been subjected to statistical analysis and this shows a significant difference between these two groups. Little inhibition of small bowel motility is seen in the third group (Table II).

Three patients in whom vagotomy was attempted were placed in the second group, as indicated in 
TABLE I

EFFECT OF OPERATION ON SMALL BOWEL MOTILITY

Vagotomy with Drainage Procedure

\begin{tabular}{|c|c|c|c|c|c|c|c|}
\hline $\begin{array}{l}\text { Case } \\
\text { No. }\end{array}$ & Operation & $\begin{array}{l}\text { Time for } \\
\text { Return of } \\
\text { Peristalsis } \\
\text { (hr.) }\end{array}$ & $\begin{array}{l}\text { Time for Pill } \\
\text { Excretion } \\
\text { (days) }\end{array}$ & $\begin{array}{l}\text { Case } \\
\text { No. }\end{array}$ & Operation & $\begin{array}{l}\text { Time for } \\
\text { Return of } \\
\text { Peristalsis } \\
\text { (hr.) }\end{array}$ & $\begin{array}{l}\text { Time for Pill } \\
\text { Excretion } \\
\text { (days) }\end{array}$ \\
\hline 1 & Vagotomy and pyloroplasty & $4 \cdot 7$ & 5 & 12 & Polya & $2 \cdot 0$ & 8 \\
\hline 2 & Vagotomy and gastrojejunostomy & $15 \cdot 0$ & - & 13 & Gastrojejunostomy & $3 \cdot 0$ & 4 \\
\hline 3 & Vagotomy and pyloroplasty & $11 \cdot 0$ & 7 & 14 & Polya & $9 \cdot 5$ & 9 \\
\hline 4 & Vagotomy and pyloroplasty & $25 \cdot 0$ & 7 & 15 & Polya & $5 \cdot 0$ & 6 \\
\hline 5 & Vagotomy and pyloroplasty & $4 \cdot 0$ & 8 & 16 & Polya & $3 \cdot 3$ & 7 \\
\hline 6 & Vagotomy and pyloroplasty & $4 \cdot 0$ & - & 17 & Pylorotomy & $4 \cdot 5$ & 5 \\
\hline 7 & Vagotomy and pyloroplasty & $18 \cdot 0$ & 5 & 18 & Pylorotomy & $2 \cdot 8$ & - \\
\hline 8 & Vagotomy and pyloroplasty & $13 \cdot 5$ & 6 & 19 & Billroth I & $4 \cdot 3$ & 11 \\
\hline 9 & Vagotomy and pyloroplasty & $9 \cdot 0$ & 5 & 20 & Pyloroplasty ${ }^{1}$ & $4 \cdot 3$ & 7 \\
\hline 10 & Vagotomy and pyloroplasty & $3 \cdot 5$ & 6 & 21 & Pyloroplasty ${ }^{1}$ & $3 \cdot 0$ & 5 \\
\hline \multirow[t]{2}{*}{11} & Vagotomy and pyloroplasty & $4 \cdot 5$ & 7 & 22 & Pyloroplasty ${ }^{1}$ & $4 \cdot 8$ & 4 \\
\hline & Mean & $10 \cdot 2$ & $6 \cdot 2$ & & Mean & $4 \cdot 2$ & $6 \cdot 7$ \\
\hline
\end{tabular}

Comparison of columns 3 and $7 t=2.7 p>0.02$

${ }^{1}$ Indicates incomplete vagotomy

Comparison of columns 4 and $8 t=0.69 p>0.5$

Gastric Operations without Vagotomy

TABLE II

EFFECT OF OPERATION WITHOUT VISCERAL MANIPULATION ON SMALL BOWEL MOTILITY

\begin{tabular}{llcc} 
Case No. & Operation & $\begin{array}{l}\text { Time for Return of } \\
\text { Peristalsis (min.) }\end{array}$ & $\begin{array}{l}\text { Time for Pill Excretion } \\
\text { (davs) }\end{array}$ \\
\hline 23 & Hernia repair & 40 & 4 \\
on Return (cm. HzO)
\end{tabular}

TABLE III

COMPARISON OF THE HEIGHT OF PERISTALTIC WAVES AT THE TIME OF REAPPEARANCE

\begin{tabular}{|c|c|c|c|}
\hline \multicolumn{2}{|c|}{$\begin{array}{l}\text { Vagotomy with Drainage } \\
\text { Procedure }\end{array}$} & \multicolumn{2}{|c|}{$\begin{array}{l}\text { Gastric Operations without } \\
\text { Vagotomy }\end{array}$} \\
\hline $\begin{array}{l}\text { Case } \\
\text { No. }\end{array}$ & $\begin{array}{l}\text { Height of Peristaltic } \\
\text { Waves on Return } \\
\left(\mathrm{cm} . \mathrm{H}_{2} \mathrm{O}\right)\end{array}$ & $\begin{array}{l}\text { Case } \\
\text { No. }\end{array}$ & $\begin{array}{l}\text { Height of Peristaltic } \\
\text { Waves on Return } \\
\left(\mathrm{cm} . \mathrm{H}_{2} \mathrm{O}\right)\end{array}$ \\
\hline $\begin{array}{r}1 \\
2 \\
3 \\
4 \\
5 \\
6 \\
7 \\
8 \\
9 \\
10 \\
11\end{array}$ & $\begin{array}{l}27 \cdot 2 \\
14.6 \\
22 \cdot 8 \\
17 \cdot 1 \\
29.4 \\
21 \cdot 4 \\
18 \cdot 0 \\
20 \cdot 4 \\
19.9 \\
26.8 \\
24.4\end{array}$ & $\begin{array}{l}12 \\
13 \\
14 \\
15 \\
16 \\
17 \\
18 \\
19 \\
20 \\
21 \\
22\end{array}$ & $\begin{array}{l}17 \cdot 8 \\
16.7 \\
22.8 \\
19.4 \\
20 \cdot 8 \\
21.4 \\
14.5 \\
26.9 \\
28.6 \\
14.5 \\
23.9\end{array}$ \\
\hline Mean & $22 \cdot 0$ & Mean & $20 \cdot 7$ \\
\hline
\end{tabular}

Table I, since a positive insulin test showed that complete vagal section had not been obtained. It is of particular interest to note that these three patients were among those who most rapidly regained small bowel motility. Two of the patients (nos. 14 and 15) in the second group in whom motility returned most slowly had been treated by a Polya gastrectomy. This may be due to division of vagal fibres during high transection of the stomach.
The height of the peristaltic waves was calculated by reference to the pressure calibration of the capsule obtained before each study. There is no apparent or significant difference between any two of the three groups (Tables II and III).

The times taken for the radio-pill to be excreted are shown in Tables I and II; in this respect also, no apparent or statistical difference was found. This provides further evidence that the effect of vagotomy is at most transitory, and effective transport is similar in all groups.

\section{DISCUSSION}

Although the mean duration of inhibition of small bowel motility after vagotomy is more than twice that following gastric operations which do not involve section of the vagus nerves, the mean value of 10 hours in our series is surprisingly brief and this finding is of both physiological and practical interest. From the physiological viewpoint these results confirm that vagal control of small bowel motor activity is comparatively slight and indicates the major role played by intrinsic nerve mechanisms mediated by the myenteric nerve plexuses of Auerbach and Meissner. In view of the lack of small bowel ileus in our patients having non-gastric 
operations, confirming similar results by other workers (Wells, Rawlinson, Tinckler, Jones, and Saunders, 1961), analgesic and anaesthetic medication (common to the three groups) can be discounted as a major contributory factor. From the practical viewpoint, the small intestine seems to be capable of transporting its contents within 24 hours of operation. This is of clinical import when considered in relation to the findings of Cox, Ross, and Kay (1962), namely, that water and simple sugars instilled into the jejunum 18 hours after gastric operation (including vagotomy) are capable of being absorbed. Our results therefore lend support to the recent tendency to replace post-operative gastric suction and intravenous fluid therapy by early feeding after most gastric operations (Welbourn and Johnston, 1961). After vagotomy, which probably results in more prolonged gastric motor inhibition, early feeding may best be given via a temporary gastrostomy, one limb of a doublebarrelled tube being placed in the duodenum (pyloroplasty) or in the jejunum (gastrojejunostomy).

Detailed studies of gastric motility beginning immediately after vagotomy are now in progress. It is clearly imperative that the telemetering device remain within the stomach and several of our radiopills have been adapted so that they can be sutured to the gastric mucosa by means of catgut (Watson et al., 1962).

Throughout this investigation we have been impressed by the simplicity of recording pressure changes in the small bowel and the comfort afforded to the patient by the radio-telemetering technique. No claim can yet be made that the radio-pill is of value in diagnosis but this study indicates that its place as an important addition to research techniques is assured.

We wish to express our thanks to Miss $\mathrm{D}$. Wemm, Mr. H. Wood, and Mr. W. Dyson for their technical help, Mr. D. Bowen and Miss Z. Hinchliffe for preparing the figures, and Miss C. Creasey for typing the script. This work has been supported by the research funds of the United Sheffield Hospitals and the Sheffield Regional Hospital Board.

\section{REFERENCES}

Baker, L. W., and Dudley, H. A. F. (1961). Auscultation of the abdomen in surgical patients. Lancet, 2, 517-519.

Code, C. F., Hightower, N. C., and Morlock, C. G. (1952). Motility of the alimentary canal in man. Amer. J. Med., 13, 328-351.

Cox, A. G., Ross, B., and Kay, A. W. (1962). Studies on the effect of vagotomy on absorption in man. Gut, 3, 96.

Hollander, F. (1946). The insulin test for the presence of intact nerve fibers after vagal operations for peptic ulcer. Gastroenterology, 7, 607-614.

Illingworth, C. F. W., and Kay, A. W. (1947). Vagotomy in the treatment of peptic ulcer. Edinb. med. J., 54, 540-544.

Kay, A. W. (1947). Effect of water on gastric motility. Lancet, 1, 448-450.

Rowlands, E. N., and Wolff, H. S. (1960). The radio pill. Telemetering from the digestive tract. Brit. Communicat. Electron., 7, 598-601.

Watson, B. W., Ross, B., and Kay, A. W. (1962). Telemetering from within the body using a pressure-sensitive radio pill. Gut, 3, 181-186.

Welbourn, R. B., and Johnston, I. D.A. (1961). The assessment and selection of elective operations for peptic ulceration. In British Surgical Practice, Surgical Progress, edited by E. R. Carling and J. Patterson Ross, p. 319. Butterworths, London

Wells, C., Rawlinson, K., Tinckler, L., Jones, H., and Saunders, J, (1961). Ileus and postoperative intestinal motility. Lancet, 2. $136-137$. 